\title{
Effects Of Revisions To The CRA In 1995 On Regulatory Enforcement
}

\author{
John Alexander, Clemson University, USA \\ Drew Dahl, Utah State University, USA \\ Michael F. Spivey, Clemson University, USA
}

\begin{abstract}
Revisions to the Community Reinvestment Act (CRA) enacted in 1995 were intended to focus greater regulatory attention on objective assessments of CRA-targeted lending. To determine the effectiveness of the revisions, we examine CRA regulatory practices, 1990 through 2000, utilizing a sample of 25,601 bank examinations. Our empirical evidence indicates that CRA examination scheduling reflected CRA ratings and real estate loan levels in the period before, but not after, enactment of the revisions, and that examination intervals, particularly for small banks, lengthened. For a subsample of banks with substandard CRA ratings, changes in loan levels influenced their odds of recovery to a satisfactory rating after, but not before, enactment of the revisions.
\end{abstract}

Keywords: Banking, Regulation, Financial Institutions

\section{INTRODUCTION}

¿

mplementation of the Community Reinvestment Act (CRA) has evolved inconsistently over time, partly as a result of recurring revisions to regulatory policy. One of the more recent revision, in 1995, was intended to focus attention "on objective, performance-based assessment standards that minimize compliance burden while stimulating improved performance (Federal Register, 2001)." It required that financial institutions reflect the principle that lending is the primary vehicle for meeting a community's credit needs--which was, of course, the original goal of the CRA when it was enacted more than 25 years ago.

Empirical research on the practical effects of the revision to the CRA in 1995 is mixed. Litan et al (2001) and Apgar and Duda (2003) examine changes in real estate mortgage lending at institutions that are subject to the CRA and at institutions that are not subject to the CRA. The former study concludes that, in the 1993 to 1999 period, "CRA lenders increased their CRA-eligible home purchase lending faster than non-CRA lenders." The latter study concludes that the effect of the CRA, in the 1993 to 2000 period, "appears to be on the decline." The discrepancy as to whether the revision encouraged behavioral change at financial institutions may be due, in part, to statistical limitations of the procedures employed. Litan et al (2001) state that their findings "are not conclusive because they do not fully control for differences between CRA and non-CRA lenders unrelated to CRA."

The analysis herein follows the spirit of these studies in attempting to measure the consequences of the revision to the CRA in 1995. But unlike Litan et al (2001), which analyzes lending outcomes as a function of variables that include regulatory factors, we analyze regulatory outcomes as a function of variables that include lending factors. Our intent is to determine whether CRA examination practices changed after 1995 in ways consistent with the intent of the revision. We consider, alternatively, potential changes in how regulators scheduled CRA compliance examinations and potential changes in how regulators disciplined institutions with observed CRA inadequacies.

Our tests for changes in CRA examination scheduling are based on 25,601 examinations, 1990 through 2000. Using a regression analysis of the interval until the next examination, we find that a reliance on lending ratios and CRA performance ratings, observed during the pre-1996 time period, was subsequently abandoned. This is consistent with the 
intent of the revision to standardize the examination process insofar as examinations were not as selectively targeted at specific institutions, as they were previously, on the basis of CRA-related criteria.

Our tests for changes in how regulators treated CRA-deficient banks are based on a subsample of 1,229 examinations which generated a substandard CRA rating. Using a probit analysis of observed changes in bank characteristics, we find that the probability of recovery to a satisfactory rating is significantly affected by changes in lending during the period after, but not before, 1996. This is consistent with the intent of the revision to institute sanctions focusing on lending performance.

The remainder of the paper is organized as follows. Section 2 discusses background material on the revisions, with particular attention devoted to the roles of lending and of regulatory subjectivity. Section 3 presents the analysis of CRA examination scheduling. Section 4 presents the analysis of CRA-deficient banks and the final section concludes.

\section{BACKGROUND}

The CRA, enacted in 1977, requires regulators "to encourage institutions to help meet the credit needs in all areas of the communities they serve (U.S. General Accounting Office, 1995)." It also requires the regulators to assess institutions' CRA performance during examinations and to consider that performance in their evaluations of institutions' applications for expanding or relocating their operations.

The CRA was implemented "inconsistently" (U.S. General Accounting Office, 1995). Among concerns prompting the revisions in 1995 were beliefs that: 1) CRA enforcement insufficiently encouraged lending to low and moderate income individuals and communities; 2) the CRA was applied too subjectively; and 3) the CRA generated excessive paperwork (U.S. General Accounting Office, 1995). The revisions were implemented over a two-year period subsequent to their enactment.

The concern that the CRA was ineffective in increasing lending was that changes in low income mortgage lending were unrelated to whether or not banks improved their assessed CRA performance. To address these concerns, the revisions in 1995 instituted performance "tests." A lending test, which is the most heavily weighted, rates institutions on the number, amount, and distribution of loans across different geographic and income groups. An investment test examines how well the institution satisfies the needs of the local community through making community investments and a service test evaluates the ability of the institution to meet the credit needs of the community through its retail service delivery system. Litan et al (2001), on the basis of case study interviews, conclude that increases in low-income lending observed in the 1995 to 1999 period were partly a result of the revisions to the CRA in 1995.

The concern that CRA enforcement was excessively subjective in the early 1990's was supported by Bierman at al (1994), Thomas (1998) and Garwood and Smith (1993), which argue examinations were inconsistent and utilized standards so vague that supervisors could basically assign any rating they want. Gunther (1999), on the other hand, finds that cross-sectional variation in CRA ratings is linked to bank-specific characteristics, while Dahl et al (2003) find that a bank's loan level, size, and affiliation status influence the scheduling and persistence of CRA rating. Both findings imply the existence of regulatory objectivity. It is important to note that all of studies cited above were limited to sample periods prior to complete implementation of the revisions to the CRA in 1995.

The regulatory burden imposed by the CRA has been criticized roundly since its enactment. Such criticism was voiced particularly by smaller institutions, which complained of "disproportionate" effects of the CRA (Garwood and Smith, 1993). As a result, the revision of the CRA in 1995 "streamlined" examination standards for small institutions (defined as an institution with assets less than $\$ 250$ million if independent or an institution with assets of less than $\$ 1$ billion if affiliated with a holding company). The objective was to reduce burdensome reporting requirements. The standards for small institutions emphasize lending and so, in that regard, are consistent with the performance tests for larger institutions. 


\section{CRA EXAMINATION SCHEDULING}

\subsection{Sample selection}

To construct the sample, we obtain CRA ratings from the Federal Financial Institution Examination Council's (FFIEC) public database for commercial banks supervised by the Federal Reserve (FED), the Federal Deposit Insurance Corporations (FDIC) and the Office of the Comptroller of the Currency (OCC), 1990 through 2001. We utilize the examinations where we can observe a bank's next examination. This allows us to measure the days until the next scheduled examination (our dependent variable). Examinations where we cannot observe the next examination through 2001 are deleted. We also require availability of bank-specific financial data from the FFIEC's Reports of Condition and Income. This screening process resulted in our sample of 25,601 observed examinations.

Table 1

Sample Grouped by CRA Compliance Rating and the Number of Years until the Next Examination* 1990-2000

Number of Years to next CRA Examination*

\begin{tabular}{|c|c|c|c|c|c|c|}
\hline CRA Rating & $0-1$ & $1-2$ & $2-3$ & $3-4$ & $4-5$ & Total \\
\hline 1 & 430 & 1423 & 1751 & 600 & 33 & 4237 \\
\hline 2 & 2198 & 7681 & 7579 & 1999 & 603 & 20060 \\
\hline 3 & 404 & 613 & 149 & 21 & 2 & 1189 \\
\hline 4 & 49 & 55 & 10 & 1 & 0 & 115 \\
\hline Total & 3081 & 9772 & 9489 & 2621 & 638 & 25601 \\
\hline
\end{tabular}

*Number of years to next CRA examination $=$ [(the number of days from the previous examination until the next examination) $/ 365$ ]. The CRA rating scheme is $1=$ outstanding, $2=$ satisfactory, $3=$ needs to improve, $4=$ substantial noncompliance.

Table 1 presents our sample segmented by CRA rating and the number of years until the next examination. Ratings are based on a four-point scale: (1) outstanding, (2) satisfactory, (3) needs to improve and (4) substantial noncompliance. More than $94 \%$ of the banks in the sample have a CRA rating of outstanding or satisfactory. With respect to examination frequency, $13 \%$ of the banks in the sample are reexamined within one year and nearly $90 \%$ are reexamined within three years. The extended periods between examination for some banks indicate that regulators failed to meet their nominal objective of examining all banks within two years (U.S. General Accounting Office, 1995). Also suggesting regulatory discretion in scheduling examinations are the observed differences in examination interval that vary by CRA rating: About $11 \%$ of banks receiving a CRA rating of outstanding were reexamined within a year, while 42 per cent banks receiving a CRA rating of substantial noncompliance were reexamined within a year.

\subsection{Discussion of the variables}

The first part of our analysis examines whether the extent of subjectivity employed by regulators in scheduling CRA examinations changed after the revision of the CRA in 1995. An ordinary least squares regression models the days until the next examination as a function of current bank-specific independent variables. We compare the results of the model generated for a sample of observations prior to the revisions, 1991 to 1996, with results for a sample of observations after the revisions, 1996 to 2001.

Characteristics of the bank that are likely to influence the scheduling of the next CRA examination are selected as independent variables. Statistically significant coefficients on independent variables would imply that regulators exercise subjectivity in examination scheduling rather than examining banks at standardized intervals.

Among independent variables is a variable representing the bank's current CRA performance rating (CRA RATING). The variable equals one for banks that received a rating of outstanding, two for satisfactory, three for needs to improve and four for substantial noncompliance. If regulators use identified ratings outcomes as a parameter in scheduling subsequent examinations, the coefficient on this variable should be positive--i.e., as compliance with the CRA deteriorates, the interval to next examination should become shorter. Such a result is suggested by our descriptions in Table 1. 
Another area of subjectivity in examination scheduling that appears to be linked to CRA-related criteria is lending. Loan generation has been found to be an important variable in determining a bank's CRA examination interval (Dahl et al, 2003) or CRA performance (Gunther, 1999). We hypothesize that banks with relatively small loan portfolios should be examined more frequently if regulators exercise discretion in scheduling. We use two different measures of loan generation. The first measure reflects real estate lending, a category that has been closely associated with the CRA. The variable is defined as the ratio of a bank's real estate loans to total assets (REAL ESTATE LOAN RATIO). The second measure is defined as the ratio of all other non-real estate loans to total assets (OTHER LOAN RATIO).

The financial condition of a bank has been hypothesized to affect CRA examination schedules (Dahl et al, 2003) or outcomes (Gunther, 1999). We use two variables to account for financial condition. Profitability (RETURN ON ASSETS) is defined to be net income divided by total assets. Capitalization (CAPITAL RATIO) is primary equity capital divided by risk-weighted assets.

Critics contend that regulatory agencies differ in CRA compliance standards and rating procedures (U.S. General Accounting Office, 1995, and Thomas, 1998). To control for inter-agency variation in CRA examination standards, we use indicator variables for the regulatory agency which supervises the examination. FDIC is set to one if the bank is supervised by the FDIC, zero otherwise, and OCC is set to one if the bank is supervised by the Office of the Comptroller of the Currency, zero otherwise. Banks regulated by the Federal Reserve represent the excluded category.

Table 2

Descriptive Statistics for the Sample Examined For CRA Compliance: $1990-2000$

\begin{tabular}{|c|c|c|c|}
\hline Variable & $\begin{array}{l}1990-1995 \\
\mathrm{~N}=20353\end{array}$ & $\begin{array}{c}1996-2000 \\
\mathrm{~N}=5248\end{array}$ & $\begin{array}{l}\text { P-value for t-test of } \\
\text { difference in means }\end{array}$ \\
\hline CRA Rating & 1.9144 & 1.7947 & 0.0001 \\
\hline Return On Assets & 0.0099 & 0.0116 & 0.0001 \\
\hline Capital Ratio & 0.0968 & 0.1034 & 0.0001 \\
\hline FED & 0.1556 & 0.2067 & 0.0001 \\
\hline FDIC & 0.7701 & 0.6604 & 0.0001 \\
\hline OCC & 0.0743 & 0.1328 & 0.0001 \\
\hline Total Loan Ratio & 0.5358 & 0.5863 & 0.0001 \\
\hline Real Estate Loan Ratio & 0.2800 & 0.3299 & 0.0001 \\
\hline Holding Company & 0.6993 & 0.7616 & 0.0001 \\
\hline SMSA Variable & 0.4003 & 0.4497 & 0.0001 \\
\hline Ln(Total Assets) & 10.6912 & 11.3814 & 0.0001 \\
\hline Days To Next Examination & 708.11 & 856.24 & 0.0001 \\
\hline
\end{tabular}

All variables (except DAYS TO NEXT EXAMINATION) are measured at the end of the year of the examination. CRA RATING equals 1 = outstanding, 2 = satisfactory, 3 = needs to improve, $4=$ substantial noncompliance; RETURN ON ASSETS $=$ net income/total assets; CAPITAL RATIO = primary capital/risk-weighted assets; FED $=1$ if FEDERAL RESERVE is principal regulator, 0 otherwise; FDIC $=1$ if FDIC is principal regulator, 0 otherwise; $\mathrm{OCC}=1$ if $\mathrm{OCC}$ is principal regulator, 0 otherwise; TOTAL LOAN RATIO = the bank's \$total loans/total assets; REAL ESTATE LOAN RATIO = the bank's \$real estate loans/total assets; HOLDING COMPANY $=1$ if the bank is a part of a bank holding company; 0 otherwise; Ln(TOTAL ASSETS) = the natural $\log$ of the total assets; SMSA VARIABLE $=1$ if bank in an SMSA, 0 otherwise; DAYS TO NEXT EXAMINATION = the number of days from the previous examination for CRA compliance until the next examination. 
Holding company status is controlled for through the use of an indicator variable (HOLDING COMPANY) that equals one if the bank is a member of a holding company, 0 otherwise. In this regard, Garwood and Smith (1993) describe differential applications of the CRA for affiliated and independent banks. Bank size may affect the interval between examinations if supervisors more frequently examine large banks under the assumption that they have a more important impact on the community. To account for such an effect, we include the natural log of the bank assets (Ln(TOTAL ASSETS)). To control for location, a dummy variable (SMSA) indicates operation in a standard metropolitan statistical area. It is possible that the level of community involvement in CRA issues is greater in urban areas.

Table 2 presents the descriptive statistics for our sample of banks. The FDIC supervises a majority of the banks in the sample. On average, real estate loans account for a minority, and non-real estate loans account for a majority, of assets. Across the two periods, before and after 1995, loan ratios increase, CRA ratings decline, profitability worsens, capitalization improves. Examination intervals are significantly longer post 1995, increasing by nearly 150 days.

\subsection{Empirical findings}

The regression estimates from the model of the days to the next examination are presented in Table 3 . The model in column 1, for the 1990 to 1995 period, is statistically significant and explains about 13 per cent of the variation in examination intervals. The model in column 2, for the 1996 to 2000 period, has less explanatory power. This may be the result of lesser discretion exerted by regulators after the 1995 revisions.

Examining the coefficients in column one, before enactment of the CRA revisions in 1995, we find evidence that banks with better CRA ratings have longer intervals to their next examination, as hypothesized. This suggests that regulators selectively targeted banks for reexamination based on CRA rating prior to enactment of the CRA revisions in 1995. The coefficient on the variable for real estate lending is positive and significant, which indicates that banks with smaller real estate loan portfolios, relative to assets, were targeted for more frequent examination. This finding implies that regulators exercised subjectivity in directing examination resources at banks with observed lending inadequacies. Banks with lower capital ratios are examined sooner, which indicates that financial performance is positively related to examination intervals (although the coefficient on profitability, another indicator of performance, was insignificant). Banks supervised by the FDIC and the OCC are reexamined sooner than banks supervised by the Federal Reserve.

Banks in urban areas were examined less frequently, which is contrary to our supposition that rural banks may be subject to less public scrutiny. Bank size and affiliation status do not affect examination intervals. These results may reflect interactions of size, status and location.

The second column of Table 3 presents results of the model for the period after enactment of the CRA revision in 1995. The coefficients on the regulatory variables (FDIC and OCC) are similar in sign and statistical significance to those reported in column 1 . This suggests that the revision did not materially alter the relative incidence of examination scheduling by regulator.

An important difference between the two sets of results is that the coefficients on capitalization, CRA rating and real estate lending are no longer statistically significant. This indicates that regulators exercised less discretion, on these important CRA-related criteria, in scheduling examinations after enactment of the revision to the CRA in 1995. The revision, therefore, appears to have been successful in their stated goal to standardize CRA enforcement.

Another difference in the two periods is that the size variable is negative and significant, which indicates that bigger banks are examined more frequently. This is a likely result of the more identifiable performance guidelines and "streamlined" performance standards for small institutions that were part of the revision to the CRA in 1995. It also is likely a result of the Gramm-Leach-Bliley Financial Modernization Act of 1999, which decreased the frequency of examination for small banks with adequate CRA ratings (supplementary tests, however, show that the increase was not limited to the post-1999 period). 
Table 3

Ordinary Least Squares Regression Examining the Days to Next Examination 1990-2000

\begin{tabular}{|c|c|c|}
\hline Variable & $\begin{array}{c}1990-1995 \\
\text { Coeff. }\end{array}$ & $\begin{array}{c}1996-2000 \\
\text { Coeff. }\end{array}$ \\
\hline Intercept & $\begin{array}{c}890.35^{*} \\
(21.46) \\
\end{array}$ & $\begin{array}{c}1314.50^{*} \\
(61.97) \\
\end{array}$ \\
\hline Cra Rating & $\begin{array}{c}-107.07 * \\
(4.28) \\
\end{array}$ & $\begin{array}{c}-19.61 \\
(11.48) \\
\end{array}$ \\
\hline Real Estate Loan Ratio & $\begin{array}{c}145.03^{*} \\
(19.19) \\
\end{array}$ & $\begin{array}{c}9.31 \\
(53.81) \\
\end{array}$ \\
\hline Other Loan Ratio & $\begin{array}{c}26.39 * * \\
(13.79) \\
\end{array}$ & $\begin{array}{c}44.03 \\
(42.91) \\
\end{array}$ \\
\hline Return On Assets & $\begin{array}{c}318.64 \\
(205.31) \\
\end{array}$ & $\begin{array}{c}145.59 \\
(645.25) \\
\end{array}$ \\
\hline Capital Ratio & $\begin{array}{l}310.01 * \\
(55.39) \\
\end{array}$ & $\begin{array}{c}80.80 \\
(146.46) \\
\end{array}$ \\
\hline FDIC & $\begin{array}{c}-237.16^{*} \\
(5.35) \\
\end{array}$ & $\begin{array}{c}-92.51 * \\
(13.35) \\
\end{array}$ \\
\hline OCC & $\begin{array}{c}-187.19^{*} \\
(7.44) \\
\end{array}$ & $\begin{array}{c}-275.53^{*} \\
(15.91) \\
\end{array}$ \\
\hline Holding Company & \begin{tabular}{r|}
-3.50 \\
$(4.33)$ \\
\end{tabular} & $\begin{array}{l}-14.59 \\
(12.99) \\
\end{array}$ \\
\hline Ln(Total Assets) & $\begin{array}{c}0.66 \\
(1.54)\end{array}$ & $\begin{array}{c}-32.33 * \\
(4.24) \\
\end{array}$ \\
\hline SMSA Variable & $\begin{array}{l}9.68 * * \\
(4.14) \\
\end{array}$ & $\begin{array}{c}3.48 \\
(11.49) \\
\end{array}$ \\
\hline Observations & 20353 & 5248 \\
\hline Adjusted $\mathrm{R}^{2}$ & 0.1313 & 0.0768 \\
\hline
\end{tabular}

The dependent variable, DAYS TO NEXT EXAMINATION = the number of days from the examination for CRA compliance until the next examination. All variables (except DAYS TO NEXT EXAMINATION) are measured at the end of the year of the examination. CRA RATING equals $1=$ outstanding, $2=$ satisfactory, $3=$ needs to improve, $4=$ substantial noncompliance; ); REAL ESTATE LOAN RATIO = the bank's \$real estate loans/total assets; OTHER LOAN RATIO = (\$total loans - \$real estate loans)/total assets; RETURN ON ASSETS = net income/total assets; CAPITAL RATIO = primary capital/risk-weighted assets; FDIC = 1 if FDIC is principal regulator, 0 otherwise; OCC $=1$ if OCC is principal regulator, 0 otherwise (FED is the excluded set); HOLDING COMPANY = 1 if the bank is a part of a bank holding company; 0 otherwise; $\operatorname{Ln}($ TOTAL ASSETS $)=$ the natural log of the total assets; SMSA VARIABLE = 1 if bank in an SMSA, 0 otherwise;

Standard errors (heteroscedastically consistent following White, 1980) are in parentheses.

*Significant at the $1 \%$ confidence level.

**Significant at the $5 \%$ confidence level.

Overall, our results for tests of CRA examination scheduling imply that a reliance on lending ratios and CRA performance ratings, observed during the pre-1996 time period, was subsequently abandoned. This appears to be consistent with the intent of the revision to standardize the examination process insofar as CRA examinations are scheduled more closely on a presumably calendar-driven basis rather than being selectively targeted at specific institutions on the basis of CRA-related criteria. It reflects a shift toward objectivity along a continuum in CRA enforcement earlier described by the U.S. General Accounting Office (1995). The latter study argued that "success in lessening problems related to inconsistent examination largely depends on how effectively examiners exercise discretion."

\section{CRA-DEFICIENT BANK RECOVERY}

\subsection{Methodology}

The second part of our analysis examines the likelihood that a bank with a substandard rating--those which are identified as needs to improve or substantial noncompliance--recover to a rating of satisfactory or outstanding by their 
next examination . Utilizing a probit model, we model the odds of recovery as a function of bank-specific independent variables. As was the case in the first part of our analysis, we isolate differences in coefficients on the variables across the two sample periods, before and after the 1995 CRA revisions.

The independent variables are the same as those used in the analysis of CRA examination scheduling with two exceptions. First, the levels of real estate loans and other loans, in the earlier model, are replaced by the percentage change in real estate loans and other loans. This focuses attention on how regulators encourage banks to change their lending behavior as compared to how they assess an inherited level of lending. Second, we have omitted the CRA rating variable because of the limitation of this subsample to substandard ratings.

Table 4 presents information on recovery patterns for the banks with substandard CRA ratings. In the years prior to the revisions in 1995, banks that recovered from a substandard CRA rating decreased lending, in both the real estate and non real estate categories, relative to banks that did not recover. In the period after the revisions, the situation is reversed--recovered banks had greater lending growth in both categories (although only the difference in the real estate category is statistically significant at the one per cent level). Recovered banks in the post -1995 time period also had greater lending growth in both categories when compared to the recovered banks in the pre-1995 time period (although, again, only the difference in the real estate category is statistically significant at the one per cent level). These univariate comparisons suggest that the revisions were effective in focusing the attention of regulators on the lending behavior for those banks with observed performance inadequacies.

Table 4

Comparison of Means for Measures of Lending Activity of CRA

Substandard* Banks Grouped by Time Period and Whether or Not Recovery Occurred by the Next Examination

\begin{tabular}{|c|c|c|c|c|}
\hline & \multicolumn{2}{|c|}{ Years } & \multicolumn{2}{|c|}{ Years } \\
\hline & \multicolumn{2}{|c|}{ 1990-1995 } & \multicolumn{2}{|c|}{ 1996-2000 } \\
\hline Lending Activity Variable & Recovery & No Recovery & Recovery & No Recovery \\
\hline Change in Real Estate Loans / Assets & $-0.038^{\mathrm{b}}$ & -0.010 & 0.044 & $0.006^{\mathrm{a}}$ \\
\hline Change in Other Loans / Assets & -0.017 & -0.038 & 0.011 & 0.009 \\
\hline Number of Banks & 833 & 251 & 83 & 62 \\
\hline
\end{tabular}

*Substandard is defined as receiving a CRA rating of 3 or 4 . The CRA rating scheme is $1=$ outstanding, $2=$ satisfactory, $3=$ needs to improve, $4=$ substantial noncompliance. Recovery is defined as indicator variable $=1$ if the bank attains a CRA rating of 2 by the next examination, 0 if not.

Change in Real Estate Loans / Assets = change from the year of the initial examination until the next examination in the bank's \$real estate loans/total assets; Change in Other Loans / Assets = change from the year of the initial examination until the next examination in the bank's (\$total loans - \$real estate loans)/total assets. Reexaminations that occurred during same year as initial examination are not included in this subsample since we are using end of the year annual data for our lending measures. We also lost observations in the computation of the change variable.

${ }^{a}$ The mean of the sample of banks that did not recover is significantly different at the $1 \%$ level than the mean of the sample of banks that recovered during the same time period.

${ }^{\mathrm{b}}$ The mean of the sample of banks that recovered during the 1990-1995 time period is significantly different at the $1 \%$ level than the mean of the sample of banks that recovered during the 1996-2000 time period.

\subsection{Empirical findings}

Table 5 presents the estimates from the probit model estimating the likelihood of a substandard (non-compliant) bank recovering by the next examination. In the period prior to enactment of the CRA revisions, in column 1, the odds of recovery are positively affected by profitability (RETURN ON ASSETS) and capitalization (CAPITAL RATIO). Gunther (1999) previously had hypothesized a relationship between CRA rating and financial condition.

The variable representing the change in lending in the real estate category (CHANGE IN REAL ESTATE LENDING) does not significantly influence the chances of recovery. This suggests that, in the period prior to the revisions to the CRA, regulators apparently were unable, or unwilling, to link rating recovery with improvement in lending performance. This is consistent with Dahl et al (2003). Banks supervised by the OCC are more likely to recover 
than banks supervised by the Federal Reserve. The positive effect that the OCC has on the probability of recovery supports the finding of the U.S. GAO (1995) that the reduction in the number of poorly rated banks was greatest for those banks supervised by the OCC.

Table 5

Probit Estimation of the Odds of Recovery for CRA Substandard Banks

\begin{tabular}{|l|c|c|}
\hline \multicolumn{1}{|c|}{ Variable } & $\begin{array}{c}\text { 1990-1995 } \\
\text { Coeff. }\end{array}$ & $\begin{array}{c}\text { C96-2000 } \\
\text { Coeff. }\end{array}$ \\
\hline Intercept & -0.76 & $-3.39^{*}$ \\
& $(0.72)$ & $6.46^{*}$ \\
\hline Change In Real Estate Loan Ratio & -0.44 & $(2.62)$ \\
& $(0.40)$ & 2.85 \\
\hline Change In Other Loan Ratio & -0.17 & $(2.39)$ \\
\hline Return On Assets & $(0.46)$ & -12.75 \\
& $22.21 *$ & $(17.56)$ \\
\hline Capital Ratio & $(5.73)$ & $3.31 * *$ \\
& $2.58^{*}$ & $(1.62)$ \\
\hline FDIC & $(0.77)$ & 5.01 \\
& 5.14 & $(6.26)$ \\
\hline OCC & $(6.15)$ & 6.14 \\
& $1.02^{* *}$ & $(9.84)$ \\
\hline Holding Company & $(0.48)$ & 0.09 \\
& 0.23 & $(0.25)$ \\
\hline Ln(Total Assets) & $(0.13)$ & 0.09 \\
& -0.04 & $(0.10)$ \\
\hline SMSA Variable & $(0.05)$ & $0.59^{* *}$ \\
\hline Observations & -0.15 & $(0.25)$ \\
\hline Log Likelihood & $(0.14)$ & 145 \\
\hline
\end{tabular}

The dependent variable, RECOVER $=1$ if the bank recovered by the next examination, 0 if not. CHANGE IN REAL ESTATE LOAN RATIO = change from the year of the examination until the next examination in the bank's \$real estate loans/total assets; CHANGE IN OTHER LOAN RATIO = change from the year of the examination until the next examination in the bank's (\$total loans - \$real estate loans)/total assets; RETURN ON ASSETS = net income/total assets; CAPITAL RATIO = primary capital/risk-weighted assets; FDIC $=1$ if FDIC is principal regulator, 0 otherwise; $\mathrm{OCC}=1$ if $\mathrm{OCC}$ is principal regulator, 0 otherwise (FED is the excluded set); HOLDING COMPANY = 1 if the bank is a part of a bank holding company; 0 otherwise; ); Ln(TOTAL ASSETS) = the natural $\log$ of the total assets; SMSA VARIABLE $=1$ if bank in an SMSA, 0 otherwise.

Standard errors in parentheses.

*Significant at the $1 \%$ level.

**Significant at the $5 \%$ level.

The final column of Table 5 presents results for the sample of observations after the CRA revisions. One difference is that location in an urban area (SMSA VARIABLE) increases the odds of recovery. This may be related, in part, to the observation by Litan et al (1999) that low income borrowers relocated to suburban markets, which may have rendered recovery relatively easier than before in urban areas. The odds of recovery are again positively affected by capitalization (CAPITAL RATIO) but not by profitability (RETURN ON ASSETS).

The size variable is not significant. This suggests that the revisions, which appear to have lengthened examination intervals for small banks relative to large banks (shown in Section 3), did not impact the likelihood of recovery of CRA-deficient banks (supplementary tests show that this result was not dependent on the period after passage of the Gramm-Leach-Bliley Act). 
The most important difference in the results across the two samples is the significantly positive coefficient on the change in real estate lending variable. This is consistent with the results presented in Table 4, suggesting that following the revision in 1995, regulators apparently were more attentive to real estate lending, the category of loans most closely associated with the CRA, in determining whether substandard banks were able to improve their rating. This is consistent with the intent of the revision to improve performance with "more effective sanctions (U.S. General Accounting Office, 1995)," which focus, particularly, on lending outcomes.

\section{CONCLUSION}

Revisions to the CRA enacted in 1995, and implemented over the following two years, moved implementation by regulators "toward standardizing, quantifying and objectifying performance criteria (Apgar and Duda, 2003)." To help assess whether or not regulators have responded as intended, we examine their CRA regulatory practices, 1990 through 2000. Our methodology is designed to identify changes in regulatory behavior after 1995. It has the advantage, relative to prior research, of an extensive sample of 25,601 observations and a sample period that encompasses several years of post-revision data.

We find evidence that CRA examination scheduling reflected CRA ratings and real estate loan levels in the period before, but not after, enactment of the revisions, and that examination intervals lengthened. We also find evidence that, for the subsample of 1,229 banks given a substandard CRA rating, changes in loan levels positively influenced their odds of recovery to a satisfactory rating in the time period after, but not before, the revisions.

Our results appear to be generally consistent with stated objectives of the 1995 CRA revisions: 1) to standardize the examination process; 2) to focus on lending performance and 3) to reduce regulatory burdens, particularly for small banks. They are relevant to an ongoing review of CRA regulations (Federal Register, 2001) that seeks to "determine whether, and if so, how, the regulations should be amended to better evaluate financial institutions' performance under the CRA."

\section{AUTHOR INFORMATION}

Dr. Michael Spivey, Clemson University earned his PhD from the University of Tennessee. He teaches undergraduate and MBA courses in the areas of financial institutions and markets, corporate finance and the management of financial institutions. Dr. Spivey has published widely in the areas of commercial banking and corporate finance. His work has appeared in many of the top journals in Banking and Finance. Presently, his research and consulting activities focus on issues relating to bank regulation and small business valuation.

Dr. Drew Dahlv is the Harold and Ruth Dance Professor of Finance at Utah State University, where he has taught for more than 20 years. His research interests are banking and international finance. He has a doctorate from the University of Tennessee and an undergraduate degree from the University of Florida. He teaches in the areas of financial institutions and markets, business finance, corporate finance and international finance.

Dr John C. Alexander, Jr. is the Breazale Professor of Investments and a Spiro Fellow of Leadership and Entrepreneurship at Clemson. He teaches graduate and undergraduate investments and corporate finance. He earned his Doctor of Philosophy in Finance from Florida State University in 1991, Master of Business Administration from Stetson University in 1985 and his Bachelor of Business Administration in Finance from Stetson University in 1984. His research interests are primarily in the areas of investments and corporate finance.

\section{REFERENCES}

1. Apgar, W. and M. Duda, 2003. The Twenty-Fifth Anniversary of the Community Reinvestment Act: Past Accomplishments and Future Regulatory Challenges. Economic Policy Review, Federal Reserve Bank of New York (forthcoming).

2. Bierman, L., D. Fraser and A. Zardkoohi, 1994. The Community Reinvestment Act: A Preliminary Empirical Analysis, Hastings Law Journal 45, 383-412. 
3. Dahl, D., D. Evanoff and M. Spivey, 2003. The Timing and Persistence of CRA Compliance Ratings. Journal of Financial Services Research 23: 113-132.

4. Federal Register, 2001. Proposed Rules, Community Reinvestment Act Reglulations, Vol 66, No. 139, 12 CFR Part 563-e.

5. Garwood, G.L. and D.S. Smith, 1993. The Community Reinvestment Act: Evolution and Current Issues. Federal Reserve Bulletin 79, 251-67.

6. Gunther, J.W., 1999. Between a Rock and a Hard Place: the CRA-Safety and Soundness Pinch. Economic and Financial Review, Federal Reserve Bank of Dallas (Second Quarter), 32-41.

7. Litan, R., N. Retsinas, E. Belsky, G. Fauth, M. Kennedy and D. Leonard, 2001. The Community Reinvestment Act After Financial Modernization: A Final Report. U.S. Department of the Treasury, Washington, D.C.

8. Thomas, K.H., 1998. The CRA Handbook. McGraw-Hill: New York.

9. U. S. General Accounting Office, 1995. Community Reinvestment Act: Challenges Remain to Successfully Implement CRA. Washington, D. C.

10. White, H., 1980. A Heteroscedasticity-Consistent Covariance Matrix Estimator and a Direct Test of Heteroscedasticity. Econometrica 48, 817-838. 